\title{
ELABORACIÓN Y EVALUACIÓN DE SUERO COSTEÑO CON ADICIÓN DE Lactobacillus lactis
}

\section{PREPARATION AND EVALUATION OF SUERO COSTEÑO WITH ADDITION OF Lactobacillus lactis}

\section{*Granados C. Clemente ${ }^{1}$, Torrenegra A. Miladys², Corrales María ${ }^{3}$.}

\begin{abstract}
${ }^{1}$ Ingeniero de Alimentos. Magister en Ciencias y Tecnología de Alimentos, docente del programa de Ingeniería de Alimentos, Grupo de investigación Ingeniería, Innovación, Calidad Alimentaria y Salud (INCAS).

Universidad de Cartagena, Cartagena, Colombia. Teléfono: (575)6699771 Celular: (57)3158332900.

2 Ingeniera de Alimentos. Magister en Ciencias y Tecnología de Alimentos, Grupo de Investigación de Biotecnología e Innovación (GIBEI). Centro de Comercio y Servicios, Regional Bolívar (SENA), Cartagena, Colombia.

${ }^{3}$ Ingeniera de Alimentos. Joven investigador del programa de Ingeniería de Alimentos, Grupo de investigación Ingeniería, Innovación, Calidad Alimentaria y Salud (INCAS). Universidad de Cartagena, Cartagena,

Colombia.
\end{abstract}

Recibido: Julio 24 de 2016; Aceptado 25 de octubre de 2016

\section{RESUMEN}

En Colombia, el sector lácteo a pesar de ser considerado como estratégico y jugar un papel importante dentro del sector agropecuario y la economía del país, siendo el suero costeño un producto artesanal autóctono de la región caribe colombiana, obtenido por la fermentación natural de la leche cruda, por lo que el objetivo de la presente investigación fue la de elaborar y evaluar el suero costeño con adición de Lactobacillus lactis con el fin de darle un valor agregado. Se evaluaron 


\begin{abstract}
@ (LIMENTECH CIENCIA Y TECNOLOGÍA ALIMENTARIA ISSN 1692-7125. Volumen 14 No. 2, p. 89 - 97, año 2016 Facultad de Ingenierías y Arquitectura Universidad de Pamplona

*Autor a quien debe dirigirse la correspondencia: Clemente GranadosConde $^{1 *}$, Correo electrónico:

las características fisicoquímicas, microbiológicas y reológicas del producto elaborado en cumplimiento de las Normas Colombianas. El suero costeño elaborado obtuvo un contenido de: grasa (18\%), cloruros (1.872 $\%), \mathrm{pH}(4.3)$, densidad (1.032 $\left.\mathrm{gcm}^{-3}\right)$ y acidez $(0.75 \%$ ácido láctico) y los recuentos microbiológicos indicaron una población $<10 \mathrm{UFC} / \mathrm{g}$. de E. coli. Se puede concluir que las características fisicoquímicas y bromatológicas del suero costeño elaborado se encontraron dentro de los parámetros lo establecido por las Normas Colombianas.

Palabras clave: Lactobacillus lactis, suero costeño.

\section{ABSTRACT}

In Colombia, the sector dairy despite be considered as strategic and play a paper important within the sector agricultural and the economy of the country, being the serum coastal a product craft native of the region Caribbean Colombian, retrieved by the fermentation natural of it milk raw, therefore, the objective was develop and evaluate the serum coastal with addition of Lactobacillus lactis. Characterized rheological and physicochemical, microbiological characteristics the product made in accordance with the Colombian standards. Coastal serum content of low-fat (18\%), chloride (1872), $\mathrm{pH}$ (4.3), density (1.032 $\left.\mathrm{gcm}^{-3}\right)$ and acidity $(0.75 \%$ lactic acid) and a population of $E$. colifrom $<10 U F C / g$. L can be concluded that bromatological and physicochemical characteristics of developed coastal serum were found within the parameters established by the Colombian standards.
\end{abstract}

Key words: Lactobacillus lactis, suero costeño. 


\section{INTRODUCCIÓN}

En Colombia, el sector lácteo a pesar de ser considerado como estratégico y jugar un papel importante dentro del sector agropecuario y la economía del país, puesto que se ha posicionado como el cuarto productor de leche con un volumen aproximado de 6.500 millones de toneladas por año, superado sólo por Brasil, México y Argentina. A nivel mundial, Colombia ocupa una posición privilegiada al ubicarse en el lugar número 15 dentro del ranking total de productores. En este contexto, los derivados lácteos como el suero y el queso costeño han adquirido gran importancia en la industria alimentaria, resaltando que son considerados productos básicos de consumo en la región del Caribe colombiano y una gran fuente de proteínas (Granados et al., 2009).

El suero costeño es un producto lácteo, fermentado y elaborado con leche de vaca, con una consistencia viscosa espesa debido a la concentración de sólidos totales, principalmente proteína y grasa, como consecuencia de la coagulación láctica, con adición de sal (Simanca et al., 2010). Es un producto típico de la costa Norte colombiana especialmente en la mayoría de los municipios de los departamentos de Bolívar, Sucre, Córdoba y Cesar, obtenido por la fermentación natural de la leche cruda que permite conservar sus ingredientes nutritivos para hacerlos disponibles incluso a las personas con intolerancia a la lactosa (Cueto et al., 2007; Acevedo et al., 2010). Su fermentación forma un sistema de dos fases, una líquida y otra sólida; la parte líquida es llamada lacto suero, y la sólida es conocida como suero con propiedades organolépticas deseables. El producto final es similar a la crema agria, un poco ácida y generalmente es usado como aderezo, acompañando casi todas las comidas. El proceso de fabricación del suero costeño artesanal es una actividad que se realiza en sitios improvisados, con herramientas rudimentarias de uso común en el campo, fermentaciones sin control bacteriano, almacenamiento inadecuado, poco control de variables como acidez, $\mathrm{pH}$ y temperatura. Con todas estas falencias, el suero costeño y la leche son consumidos por la gran mayoría de la población de la costa Norte colombiana. El objetivo del presente trabajo fue el de elaborar un suero costeño adicionado con Lactobacillus 
@-LiMENTECH CIENCIA Y TECNOLOGÍA ALIMENTARIA ISSN 1692-7125. Volumen 14 No. 2, p. 89 - 97, año 2016

Facultad de Ingenierías y Arquitectura

Universidad de Pamplona

lactis como alternativa para mejorar sus

características.

\section{METODOLOGÍA}

\section{Estandarización y Elaboración}

La leche destinada a la elaboración de productos lácteos fermentados se estandarizó a un porcentaje de $3.8 \%$ de grasa, se incorporó leche en polvo descremada al $0,1 \%$ de grasa con la finalidad de incrementar los sólidos y facilitar el proceso de fermentación por el incremento del sustrato (Lactosa), posteriormente se mezcló utilizando una licuadora industrial (figura 1).

Tratamiento térmico. Este proceso se llevó a cabo en una marmita con agitación constante a temperatura de $80^{\circ} \mathrm{C}$ por 20 minutos con el objetivo de destruir los microorganismos patógenos.

Enfriamiento de la leche. La leche pasterizada de enfrió a la temperatura de $30^{\circ} \mathrm{C}$ que es la ideal para éste tipo de microorganismos (mesófilos).

Inoculación. Se inoculo el $0.2 \%$ del Lactobacillus lactis ( $\mathrm{p} / \mathrm{v}$ ) marca Hansen en siembra directa con agitación constante durante 3 minutos con el objetivo de distribuir el cultivo uniformemente y activar los microorganismos (Granados et al., 2009).
Incubación. El proceso fermentativo se realizó aproximadamente durante 24 horas con los controles de $\mathrm{pH}$ y acidez, expresados en \% de ácido láctico (Granados et al., 2009).

Ruptura del coagulo. La sinéresis (desuerado) se realizó por separación del lactosuero del suero costeño por decantación utilizando un lienzo estéril.

Separación del suero. El suero costeño es separado del lactosuero por decantación hasta un $30 \%$ del volumen inicial con peso final.

Homogenización. Este proceso se realizó en la licuadora con adición de sal al $1.2 \%$ del volumen final obtenido durante 10 minutos.

Enfriamiento. Se realizó para inhibir el crecimiento bacteriano y estabilizar la acidez a los valores deseados.

Envasado. El envasado del suero se realizó en empaques herméticamente cerrados con el objetivo principal de mantener el producto seguro de agentes físicos, químicos y biológicos, además de ayudar en el transporte y presentación del mismo (Granados et al., 2009). 
Almacenamiento. Se realizó a temperaturas de $5{ }^{\circ} \mathrm{C}$, este último paso consiste en mantener las características del producto por el mayor tiempo posible (Acevedo et al., 2012).

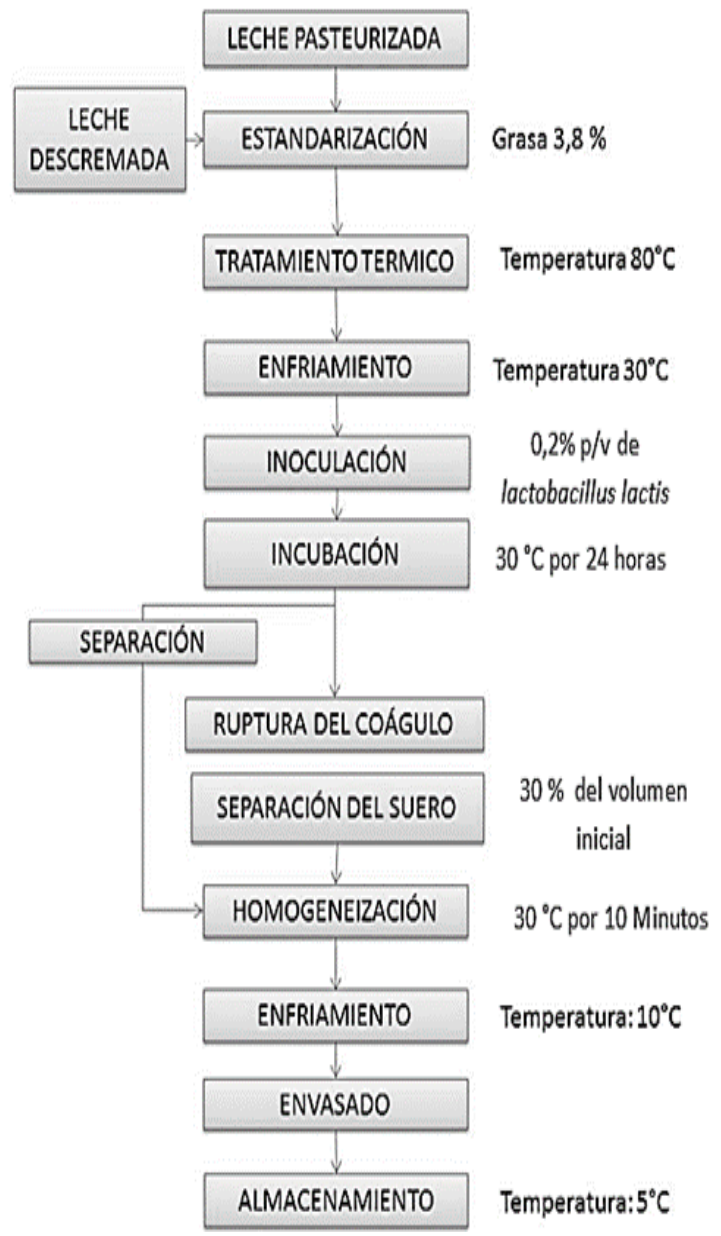

Figura 1. Diagrama de flujo de elaboración del suero costeño. Fuente: Autores.

\section{Análisis fisicoquímicos.}

Los análisis fisicoquímicos para la leche fueron: acidez, densidad, grasa, $\mathrm{pH}$, cloruros. La grasa, por el método de Gerber, NTC 4722; cloruros se hizo mediante la norma NTC 506; la densidad, por el método de lacto densimetría. La acidez se expresa como ácido láctico mediante titulación siguiendo la norma NTC 4978; se determinó el pH mediante el método $945.10 / 90$ de la AOAC adaptado (Granados et al., 2009).

\section{Análisis Microbiológico}

El recuento de Escherichia coli se llevó a cabo mediante el método de NMP (Número más probable), siguiendo la NTC 4458; para el recuento de Staphylococcus coagulasa positiva, se empleó el recuento en placa en superficie, siguiendo la NTC 4779; la detección de Salmonella spp se realizó mediante el método de recuento en placa, según la NTC 4574, y la presencia de Listeria monocytogenes se comprobó mediante el método de detección cualitativo, con la NTC 4666 (Granados et al., 2009).

\section{Análisis Reológico}

Para la prueba de viscosidad aparente se tomó $500 \mathrm{~mL}$ de suero y se midió la viscosidad a diferentes revoluciones por minuto en un viscosímetro el cual funciona a diferentes revoluciones por minutos hasta llegar a 100.

Se aplica la siguiente ecuación

$$
\tau=k \gamma^{n} \text { siendo } n<1
$$




$$
\mu_{a}=\tau / \dot{\gamma}
$$

Para estos fluidos se define un coeficiente de viscosidad aparente, como:

Remplazando queda que:

$$
\mu_{a}=\frac{k \dot{\gamma}^{n}}{\dot{\gamma}}=k \dot{\gamma}^{(n-1)}
$$

Para el presente estudio con la ayuda del software de modelamiento matemático se obtuvo que $n=0.2917, K=34.834$ y $R^{2}=0.99929$

\section{RESULTADOS}

En la tabla 1 se muestran los análisis fisicoquímicos del producto final obtenido donde los resultados obtenidos se encuentran dentro de los parámetros establecidos (Granados et al., 2009; Acevedo et al., 2010; Granados et al., 2012; Batista 2011). En lo referente al porcentaje de grasa presenta unos valores relativamente bajos debido a la adición de leche en polvo descremada lo cual incidió en éstos valores.

Tabla 1. Análisis fisicoquímicos del suero costeño.

\begin{tabular}{|c|l|l|}
\hline $\begin{array}{c}\text { Parámetros } \\
\text { Evaluados }\end{array}$ & Resultados & $\begin{array}{l}\text { Parámetros } \\
\text { Referencia }\end{array}$ \\
\hline
\end{tabular}

\begin{tabular}{|l|c|c|}
\hline $\mathbf{p H}$ & 4.3 & $4.0-4.5$ \\
\hline Acidez & 0.75 & Máximo 1.5 \\
\hline $\begin{array}{l}\text { Materia } \\
\text { grasa en } \\
\text { extracto } \\
\text { seco }\end{array}$ & $18 \%$ & $15-25$ \\
\hline Cloruros & 1.872 & Máximo 2.5 \\
\hline Densidad & $1.032 \mathrm{gcm}^{-3}$ & Mínimo \\
& & $1.030 \mathrm{y}$ \\
& & máximo \\
& & 1.033 \\
\hline
\end{tabular}

Fuente: Autores.

Las enfermedades causadas por el consumo de alimentos contaminados han surgido como una causa importante de morbimortalidad a nivel mundial. Han sido descritos alrededor de 250 agentes causantes de enfermedades transmitidas por alimentos (ETAs), entre los que se 
incluyen bacterias, virus, hongos, parásitos, priones y toxinas (Chams et al., 2010). En Colombia, en el año 2005, se reportaron por el Sistema Nacional de Vigilancia en Salud Pública, SIVIGILA (Ministerio de la Protección Social, Instituto Nacional de Salud) 7.941 casos de enfermedades trasmitidas por alimentos. De acuerdo a los resultados obtenidos en el análisis microbiológico del producto final todos se encontraron dentro de los parámetros establecidos por el Ministerio de Protección Social.

Tabla 2. Análisis microbiológico del suero costeño elaborado.

\begin{tabular}{|c|c|c|}
\hline Parámetros & Resultados & Normativa \\
\hline $\begin{array}{c}\text { Recuento de } E . \\
\text { coli UFC/g }\end{array}$ & $\begin{array}{c}<10 \\
\text { UFC/g }\end{array}$ & $<10$ UFC/g \\
\hline $\begin{array}{c}\text { Coliformes } \\
\text { fecales }\end{array}$ & $<10$ UFC/g & $<10$ UFC/g \\
\hline $\begin{array}{c}\text { Recuento de } \\
\text { Staphylococcus } \\
\text { coagulasa } \\
\text { positiva UFC/g }\end{array}$ & $<10$ UFC/g & $<100$ \\
UFC/g \\
$\begin{array}{c}\text { Salmonella /25 } \\
\text { g }\end{array}$ & Ausencia & Ausencia \\
\hline $\begin{array}{c}\text { Listeria } \\
\text { monocytogenes } \\
\text { /25 g }\end{array}$ & Ausencia & Ausencia \\
\hline
\end{tabular}

Fuente: Autores.

En lo referente a los análisis de viscosidad como se puede apreciar en la figura 2 muestra la relación viscosidad-velocidad de deformación, de acuerdo a la ley potencial con una desviación $\mathrm{R}^{2}=$ 0.99929 , por lo tanto, el suero costeño se

ajusta muy bien a este tipo de análisis matemático.

La clase de fluido del suero costeño propuesto es de tipo Pseudoplástico, ya que ve reducida su viscosidad al aumentar la velocidad de deformación y decrece con el incremento de esta hasta alcanzar un valor asintótico. La relación más simple que describe el comportamiento de los fluidos Pseudoplásticos es la denominada ley potencial o de Ostwald (Acevedo et al., 2012).

El flujo newtoniano y el adelgazamiento tipo plástico, pueden ser explicados, dado que las moléculas poliméricas dispersadas se hallan entrelazadas unas con otras y las partículas en suspensión ocupan posiciones distribuidas al azar a causa del movimiento de agitación térmica de las mismas.

Cuando tiene lugar una agitación progresiva en el seno del sistema, las cadenas poliméricas se desenredan y las partículas se alinean a lo largo de líneas de corriente. Todo ello da lugar, en definitiva, a una disminución de la fricción interna y, por tanto, de la viscosidad aparente del sistema (Acevedo et al., 2012). 


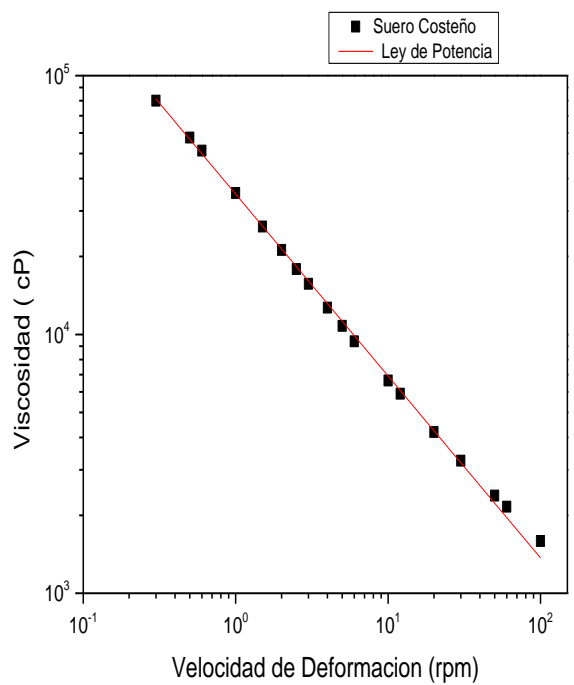

Figura 2. Viscosidad aparente del producto propuesto.

\section{CONCLUSIONES}

\section{REFERENCIAS}

Acevedo D., Rodríguez A, Fernández A. (2010) Efecto de las variables de proceso sobre la cinética de acidificación, la viabilidad y la sinéresis del suero costeño colombiano. Información Tecnológica. 21(2): 2936.

Acevedo D., Rodríguez A., Fernández, A. (2012). Determinaciones oscilatorias de baja amplitud del suero costeño. Rev. U.D.C.A Act. \& Div. Cient. 15(1): $219-225$

Chams L., Cury K., Aguas Y. (2012). Evaluación microbiológica de suero costeño y valoración higiénica en puntos de venta en Montería, Córdoba. Rev. Colombiana cienc. Anim. $4(2): 344-352$.

Cueto C., Garcés F. (2007). Preliminary studies on the microbiological characterization of lactic acid bacteria in Suero Costeño, a Colombian traditional fermented milk product. Revista latinoamericana de microbiología. 49:11-17.

Granados-Conde C., Acevedo-Correa D, Torres-Gallo R. (2012). Calidad de la leche y del suero costeño de los municipios Turbaco, Arjona y Carmen de Bolívar - Colombia. Revista 
Lasallista de Investigación. 9(2): 132137.

Herrera, Fanny A., Santos, J. B. (2015).

Perfiles de PCR-RFLP en Staphylococcus aureus Meticilinaresistentes aislados a partir de queso fresco artesanal. Revista @limentech, Ciencia y Tecnología Alimentaria. ISSN 1692-7125. Volumen 13, N². P. $54-66$.

Motta Correa, Y., Mosquera, W. J. (2015). Avances en el aprovechamiento del lacto suero como materia prima en la industria alimentaria, Revista @limentech, Ciencia y Tecnología Alimentaria. ISSN 1692-7125. Volumen $13, N^{\circ} 1 . P$.

NTC 4458, microbiología de alimentos y de alimentos para animales. Método horizontal para el recuento de coliformes o Escherichia coli o ambos. Técnica de recuento de colonias utilizando medios fluorogénicos 0 cromo génicos, 2007.

NTC 4574, microbiología de alimentos y alimentos para animales. Método horizontal para la detección de Salmonella spp, 2007.

NTC 4666. Microbiología de alimentos y alimentos para animales. Método horizontal para la detección de Listeria monocytogenes. Parte 1: método de detección, 1999.

NTC 4779. Microbiología de alimentos y alimentos para animales. Método horizontal para el recuento de estafilococos coagulasa positiva (Staphylococcus aureus y otras especies), 2007.

NTC 4978. Leche y productos lácteos. Determinación de la acidez titulable método de refencia, 2001.

PROEXPORT COLOMBIA. Sector Lácteo en Colombia. (2011). 1-18.

Rios, P. Cindy, Maldonado, M. Lida y Caballero P. Luz A. (2016). Bebida fermentada a base de arroz con adición de probióticos. Revista @limentech, Ciencia y Tecnología Alimentaria. ISSN 1692-7125. Volumen 14, N¹. P. 54 - 69.

Simanca M., Arteaga M., Pérez Y., Soto M., Salcedo J. (2010). Caracterización y estudio de la fermentación espontanea del suero costeño producido en Montería. Rev. MVZ Córdoba 15(1): 1944 - 1953. 